improve their blood flow for three or four weeks before pinch grafting.

L O SIMPSON

Department of Pathology,

University of Otago,

Dunedin,

New Zealand

1 Woodruff MFA, Simpson LO. Experimental skin grafting in rats with special reference to split skin grafts. Plast Reconstr Sur 1955; 15:451-8.

2 Simpson LO, Shand BI; Olds RJ. The effects of dietary supplementation with Efamol on the healing rate of intractable leg ulcers: a pilot study. NZ Family Physician 1986;13:68-70.

Kury PG, Ramull PW, MCColl HM. The effects prostaglandins $E_{1}$ and $E_{2}$ on the human erythrocyte as monitored by spin labels. Biochem Biophys Res Commun 1974;56:478-83.

4 Rasmussen $\mathrm{H}$, Lake W, Allen JE. The effects of catecholamines and prostaglandins upon human and rat erythrocytes. Biochim Biophys Acta 1975;411:63-73.

5 Kamada T, Yamashita T, Baba Y, et al. Dietary sardine oil increased erythrocyte membrane fluidity in diabetic patients. Diabetes 1986;35:604-11.

6 Cartwright IJ, Pockley AG, Galloway JH, Greaves M, Preston $F E$. The effects of dietary omega- 3 polyunsaturated fatty acids on erythrocyte membrane phospholipids, erythrocyte deformaon erythrocyte membrane phospholipids, erythrocyte deforma-
bility and blood viscosity in healthy volunteers. Atherosclerosis 1985;65:39-46.

7 Adair HM. Epidermal repair in chronic venous ulcers. Br F Surg 1977;64:800-4.

AUTHORS' REPLY, - We find it difficult to respond to Dr Simpson's letter as it does not address the issue of our clinical trial and contains several assertions with which we entirely disagree. Microvascular studies performed with Alison Allen and Dr Tooke in our patients have shown increased rather than impaired blood flow in patients with venous ulcers. We therefore do not agree with the basic thesis presented by Dr Simpson and believe that venous ulceration is due to persistent venous congestion leading to perivascular oedema and fibrin deposition, as indicated in our paper.

Some of the publications that Dr Simpson quotes in support of the use of Efamol oil are difficult to track down, but as far as we can ascertain they do not represent adequate controlled trials of the sort that we consider to be essential in evaluating a treatment in venous ulcers where healing and relapse may occur because of various other factors. We were surprised at the suggestion that our results might be improved with the use of Efamol treatment when the results quoted in Dr Simpson's letter indicate that ulcers in only five of 14 patients healed completely over two years, compared with a probability of healing by life table within 12 weeks of $74 \%$ with pinch skin grafting and $46 \%$ with porcine dermis. Moreover, if our study had been continued for longer, porcine dermis would have achieved a similar complete healing rate to that achieved with pinch skin grafting.

Our conclusions remain unaltered: we believe that elastic bandaging that exerts a compression of around $\mathbf{4 0 ~} \mathrm{mm} \mathrm{Hg}$ at the ankle for one week is the most important element in healing venous ulcers in ambulant patients. When the ulcer is large pinch skin grafting increases the rate of healing. The role of Efamol could be investigated in appropriate clinical trials, but we cannot support its use on the basis of the currently available evidence.

K R PoskitT Charles McCollum

Department of Surgery, London W6 8RF

\section{Respiratory health workers visiting patients with chronic respiratory disability}

SIR,-We write in reply to Dr Pearce and colleagues ( 7 March, $p$ 647). The role of our nurses mainly followed that recommended in the Royal College of Physicians report.'

There were some patients on oxygen concentrators (many were still using cylinders) and the nurses educated them about the machines and encouraged the patients to use them adequately. For patients who needed postural drainage the nurses taught them about this and encouraged them (and their spouses) to persist with it; they liaised with an existing domiciliary physiotherapy service. Naturally, a major element of the nurses' work was education about medicines and their appropriate use, including inhaler technique and the use of reserve courses of antibiotics and steroids. We showed an objective improvement in patients knowledge in this area. The nurses in the study did not take part in tuberculosis contact tracing or supervision of antituberculous chemotherapy as this was already being done by a tuberculosis health visitor, but this could be part of the nurse's role in some places.

The nurses also dealt with education about diet to reduce weight, support to give up smoking, and increase physical exercise within the capacities of the individual patients. They also dealt with some of the emotional problems common in patients with chronic disabling disease (with the support of a psychotherapist), since these sometimes caused difficulty in accepting and managing the physical aspects of the disease and its treatment.

We did not find our results discouraging. Keeping people alive and reasonably happy seems to be worth while, even though it costs money. A larger study may well show a more definite effect on mortality and clarify the question about whether the control patients really were dying at home rather than seeking help. Management of chronic illness is becoming an increasingly important part of medical practice, and we hope our small study will stimulate discussion and encourage people to undertake further work of this sort.

A COCKCROFT

A HESLOP

P BAGNALI

A GuZ

Department of Medicine,

Charing Cross and Westminster Medical School,

London W6 8RF

1 Royal College of Physicians. Disabling chest disease: prevention and care. $\mathcal{F} R$ Coll Physicians Lond 1981;15:69-87.

\section{Unemployment and mortality}

SIR,-Dr B S Smith (21 March, p 774) queries why men reported as seeking work at the time of the 1981 census should have increased mortality two years later despite our describing them as an initially healthy subset of the unemployed. This hinges on the mechanism by which they were identified from the census questions on economic activity in both 1971 and 1981. These questions were phrased so as to exclude from the category "seeking work" men who considered that a permanent illness or disability prevented them from seeking work but to include those looking for work despite health problems or whose health problems were not yet manifest. This degree of initial health selection may be expected to cause the limited, short term reductions in mortality noted in our paper; sufficient to dispel the suggestion that our sample of men had high mortality because existing ill health prevented them from working, but no more than this.

As far as the complex interrelation between smoking, personality, unemployment, and mortality are concerned, we believe that there are two fundamental flaws in the argument concerning cause and effect advanced by Dr Smith.

Firstly, the association among doctors reported by Doll and Peto between heavy smoking and subsequent mortality from suicide and cirrhosis, which they ascribed to doctors with psychological problems, cannot properly be interpreted as meaning that personality problems provide a general explanation for heavy smoking and hence smoking related diseases. This generalisation was not suggested by Doll and Peto and is not consistent with, for example, gross geographical and temporal variations in smoking habits.

Secondly, if pre-existing personality problems were the source of the association between unemployment and increased mortality we would have expected a dilution of excess mortality as unemployment levels rose between 1971 and 1981 to include more "ordinary men." As indicated in our paper, this was not the case.

K A MOSER P O GOLDBLATT A J Fox

Social Statistics Research Unit,

City University,

London EClV OHB

D R JONES

Department of Clinical Epidemiology and Social Medicine,

St George's Hospital Medical School

London SW17 0RE

1 Doll R, Peto R. Mortality in relation to smoking: 20 years' observations on male British doctors. Br Med $\mathcal{J}$ 1976;ii: 1525-36.

${ }_{*}^{*}$ This correspondence is now closed.-ED, $B M \mathcal{F}$

Fall in intraocular pressure during acute hypoglycaemia in patients with insulin dependent diabetes

SIR,-Dr B M Frier and colleagues (7 March, p 610) describe the fall in intraocular pressure after insulin induced hypoglycaemia and examine its temporal relation to adrenaline concentrations. They show that the fall in intraocular pressure preceded the maximum rise in plasma adrenaline concentration and conclude that the rapidity of change in intraocular pressure is probably mediated by autonomic innervation to the eye and not primarily by adrenaline.

The blood pressure of the patients was not measured or commented on by Dr Frier and coworkers. Production of aqueous humor and intraocular pressure are critically dependent on ocular arterial perfusion pressure. Intraocular pressure falls sharply when blood pressure is reduced, particularly below $60 \mathrm{~mm} \mathrm{Hg.}{ }^{12}$ During insulin induced acute hypoglycaemia diastolic pressure falls and variable changes in systolic pressure occur. ${ }^{3}$ The fall in intraocular pressure during acute hypoglycaemia is more likely to be due to the immediate effect of hypotension on the eye than direct autonomic innervation of the eye.

D F P LARKIN Peter Eustace

Mater Misericordiae Hospital

Dublin 7

Bill A. The effect of changes in arterial blood pressure on rate of formation of aqueous in a primate. Ophth Res 1970;1:193-200. Larkin DFP, Connolly P, Magner JB, Wood AE, Eustace P. Intraocular pressure during cardiopulmonary bypass. $\mathrm{Br} \mathcal{J}$ Ophthalmol 1987;71:177-80.

3 Marks V. Symptoms and signs. In: Marks V, Rose FC, eds. Hypoglycaemia. 2nd ed. Oxford: Blackwell, 1981:99.

AUTHORS' REPLY,-Acute insulin induced hypoglycaemia provokes well defined changes in blood pressure, comprising a rise in systolic pressure and a simultaneous fall in diastolic pressure, which start at the onset of the acute autonomic reaction and are maximal about 15 minutes later. ${ }^{1}$ The mean arterial pressure (diastolic pressure plus one third of the difference between systolic and diastolic pressures) remains unchanged. Changes in blood pressure are associated with sympathoadrenal activation and secretion of adrenaline, ${ }^{2}$ 